\title{
Northern comfort: geographical scale, locality and the evolution of networks in the Finnish metal music genre
}

\author{
Teemu Makkonen \\ School of Hospitality and Tourism Management, University of Surrey \\ Rik Medlik Building, GU2 7XH Guildford, United Kingdom \\ Email: t.makkonen@surrey.ac.uk \\ $\&$ \\ Department of Border Region Studies, University of Southern Denmark \\ Alsion 2, DK-6400 Sønderborg, Denmark. \\ Email: teemu@sam.sdu.dk
}

\begin{abstract}
There is a limited geographical literature on the evolution of networks in distinct music genres. This gap is addressed here via an analysis of empirical evidence on the Finnish metal music genre, specifically utilising a questionnaire survey of Finnish metal music bands. The results show that, in terms of networking, local buzz is more important for bands that reside in large cities compared to those from small localities. However, even small towns can host creative teams, as the bands in smaller (peripheral) localities network through extra-local (global) pipelines. Consequently, extra-local networks are at least as important as local ones for this music genre to thrive in a particular location. In addition, record deals are more important than geographical scales in explaining variances in networking within the genre. Thus, contrary to the recent literature underlining the role of geographical proximity in the creative industries, locality and geographical scale do not play such a significant role in the evolution of networks in the Finnish metal music genre.
\end{abstract}

Keywords creative industry; Finland; geographical scale; locality; metal music; network

This is an Accepted Manuscript of an article published by John Wiley \& Sons in Area on 24 JUN 2015, Vol. 47, No. 3, pp. 334-340. Available online: http://onlinelibrary.wiley.com/doi/10.1111/area.12204/abstract 


\section{Introduction}

The existing academic literature, especially psychological studies, seem to have been fixated on the negative impacts of listening to metal music, linking it to substance misuse and youth suicide (Snell and Hodgetts 2007). However, more recently the focus of academic research has moved beyond these negative connotations and there has been increasing interest in studying metal music in a broader social science context, evident, for example, in a recent upsurge in academic books on metal music (Kahn-Harris 2007; Bayer 2009; Hjelm et al. 2013). Examples of academic research on the subject include studies of the global diffusion of metal music as evidenced by the rate of founding of metal band (Mayer and Timberlake 2014; Maguire 2015), the creative networks between metal bands within a single country (Makkonen 2014), and the entrepreneurial characteristics of metal musicians (Laaksonen et al. 2011). In particular, since there are examples of spatial concentrations of varying metal music styles in distinct locations or countries, such as Birmingham (the birthplace of) heavy metal, Bay Area (San Francisco) trash metal, Tampa and Gothenburg death metal, Sunset Strip (Los Angeles) glam metal and Norwegian black metal scenes (Dunn 2004; Kahn-Harris 2004; Harrison 2010), the interplay between the global nature of the music industry and local metal scenes has been examined in several studies (Harris 2000; Kahn-Harris 2002; Baulch 2003). However, these earlier studies have mostly turned their attention to the identity of local scenes and the musical influences of local styles vis-à-vis the global music industry, while essentially neglecting the more tangible issue of the local-international networks between bands within the genre. The issues in this case study of metal music have broader resonance for other music genres and, therefore, the findings of this paper have applicability to other "alternative" music scenes.

Despite the recent interest, there is still relatively little geographical literature on music genres outside the realm of mainstream pop and rock music (Connell and Gibson 2004; Johansson and Bell 2009). The music industry has also mostly been studied in large cities (Chu 
and Leung 2013; Lange and Bürkner 2013) while, with some exceptions (Gibson and Davidson 2004), there have been relatively few studies of creative individuals in the music industry in peripheral and smaller localities. At the same time, the attention of the recent literature has shifted to the importance of local and extra-local networks (commonly referred to as "local buzz" and "global pipelines") in the evolution of distinct clusters (Bathelt et al. 2004), but this discussion still rests on a thin evidence base (Gertler and Wolfe 2006; Mould and Joel 2010). This article addresses the following research gaps: lack of research on the geography of metal music, the music industry in the periphery, and the local buzz-global pipelines metaphor in creative industries. It provides new empirical evidence on the fit of existing theories to local and extra-local networking in a geographical context in the case of the Finnish metal music genre.

Empirically the metal music genre in Finland offers an interesting case for the purpose of this study since, despite some recent examples discussed above and growing interest from the fields of sociology and cultural studies, it has remained under-studied in geographical research (Makkonen 2014). Moreover, Finland has been branded as, and is widely recognized as, one of the centres of metal music with several globally known metal music bands (Friman et al. 2013). In Finland, the capital region, i.e. the Helsinki Metropolitan Area (HMA), together with other large city regions (in terms of population) are seemingly the obvious place for musicians to reside, since they are also the main locations in Finland for concert venues, record labels and recording studios (Makkonen 2014). It is within this context that local and extralocal networks are analysed here in terms of a dichotomy between large and small localities in order to compare the importance of these networks in urban versus more peripheral settings.

The specific research aims are as follows: to explore the evolution of networks amongst Finnish metal music bands in their home region (local buzz) as well as their national and international connections (global pipelines) and the importance of city size, locality and 
geographical scale in this evolution. The results are derived from a questionnaire survey of Finnish metal music bands. These empirical data allow for the testing of the following theoretically informed (Brown et al. 2000; Braunerhjelm 2009) research question: how important are local and extra-local networks for bands located in large cities and in small localities? In addition, earlier studies have shown (Hracs et al. 2011; Hracs and Leslie 2014) that independent bands might have different preferences compared to those bands which have a record deal. The former are less tied to the traditional centres of the music industry compared to those bands which have signed a record deal. Therefore, the results are also interpreted vis$\grave{a}$-vis this background variable.

\section{The geography of the music industry and genres}

As discussed above, there are several examples of music industry and genres clustering in a particular region or a city. Creative clusters have a number of determinants related especially to the existence of external economies (Belussi and Sedita 2008), the concentration of creative individuals into cities with vibrant and tolerant living environments (Florida 2005) and the enhanced role of geographical proximity in creative industries (Asheim et al. 2007; Matters, 2012; Martin 2013). In principle, due to recent developments in digital technology, musicians are free to choose where they locate irrespective of the music infrastructure (Hracs et al. 2011), but still tend to cluster loosely around the recording industry (Florida et al. 2010). Subsequently, other talented musicians will move to the cities with vibrant music scenes (Kloosterman 2005). In short, according to the evidence (Florida and Jackson 2010; Brandellero and Pfeffer 2011; Watson 2012), the music industry is highly localised and has a tendency to agglomerate in large urban areas. For example, in Finland the metal music bands seem to cluster in the HMA (Makkonen 2014). 
Others commentators, however, contend that to become a music cluster, a city has to be sufficiently small for a high degree of connectivity and social trust to develop between the artists as well as the firms and organizations engaged in the music industry. It also has to be sufficiently large to assemble in a distinct location all the actors needed for the existence and the development of the music industry (Braunerhjelm 2009). This is essentially encompassed in the term local buzz. According to this view, medium-sized cities are in a good position to become clusters for the music industry and genres if they possess the appropriate conditions for creative engagement (Grant and Kronstal 2010). Living costs and housing prices are evidently a factor in explaining the tendency, at least amongst independent musicians, to locate outside the largest cities (Hracs et al. 2011). There are also examples of small localities taking a lead in distinct music genres (Gibson and Davidson 2004). In Finland, for example, some smaller localities that have become alternative homes for significant metal scenes with relatively large numbers of local metal bands (Makkonen 2014). However, some of these local music scenes might (typically) last only for a limited time period as exemplified by the decline of the mainstream popularity of the Seattle sound i.e. grunge (Hauge and Hracs 2010). In addition, many rural and peripheral areas understandably do not have the necessary preconditions for dense local networks (Fløysand and Jakobsen 2007). Therefore, despite the importance of the local scale, ultimately the scope of the creative industries is nothing less than global (Scott 2010): extra-local links, i.e. the global pipelines, which are posited as being extremely important in social interaction within the music industry (Brown et al. 2000), are also needed for vital and vibrant music industry clusters to emerge. Notably, as stated by Watson $(2008,12)$, "knowledge transfer within the music industry occurs simultaneously across multiple geographical scales”.

To conclude, arguably the most important underlying motives for bands to network are related to creativity and lifestyle, but also include more pragmatic reasons, that is to making a 
living out of their profession by, for example, sharing costs in equipment, touring together to attract larger audiences, and recording with guest musicians in order to increase record sales (van Heur 2009; Coulson 2012; Lange and Bürkner 2013). In this respect, engagement with different actors in the music industry is, in many cases, necessary for recording, live concert and merchandise arrangements. Therefore, within the music industry knowing who to contact in the professional community is important, and networking, is an essential strategy for musicians and bands in this respect (Asheim and Hansen 2009). However, the dynamics and evolution of these networks, characterized by local buzz and global pipelines, have rarely been studied in a geographical context (Ter Wal and Boschma 2009) let alone in relation to the music industry (Cummins-Russell and Rantisi 2012).

\section{Data and study design}

The questionnaire included questions on the background characteristics of the bands (name, record deal, name of the record company and hometown) to allow comparisons between large and small localities as well as independent bands and bands with a record deal. The six largest Finnish cities (including Helsinki, Espoo and Vantaa from the HMA as well as Tampere, Oulu and Turku) were considered to be large cities. The questionnaire (in Finnish - extracts translated by the author) was distributed to 429 Finnish metal music bands using contact details (email addresses) in the Metal from Finland (2013) database. Altogether 62 answers were received (a modest response rate of 14.5\%). When divided according to the main hometown/municipality stated in the answers (in a few cases some of the bands' musicians lived in different localities), the sample was divided into equal shares with 31 bands from large cities and 31 from small localities. Amongst these bands, 27 had a record deal, whereas 35 were considered as independent bands or bands in the demo-stage (i.e. without a record deal). 
Additionally, the questionnaire asked whether (and why) the bands had moved, or were contemplating moving, to another town.

The questionnaire also included a set of questions related to networking, inquiring how often (on a scale where $1=$ seldom and $7=$ very often) they play together with, or lend or borrow equipment to/from other local, Finnish and international bands and musicians in terms of quest performances (live and recording sessions). The questionnaire also addressed the intangible relationships inherent in touring and hanging out together. The more pragmatic networking patterns with local, Finnish and international firms and organizations engaged in the music industry were also identified in terms of their frequency. After discussions with a partner in a Finnish record company, the firms and organizations that bands and musicians are commonly engaged with were identified as being: managers, record and publishing companies, recording studios, booking agencies, sound and lighting services, concert venues, fan product vendors and copyright societies. The different questions were arranged as sum variables (reliability was tested with the Cronbach's alpha test), which allowed the comparison of different indicators with Mann-Whitney U-tests, namely the background variables; city size and record deal. The bands were also given the opportunity to express their opinions through open-ended comments to address the pros and cons of living in a small/large locality and the motives (creative, lifestyle or pragmatic) behind networking or lack of networking with other actors in the music industry.

\section{The local and extra-local networks of Finnish metal music bands}

Factors such as inexpensive training facilities, low competition and supportive local organizations were frequently mentioned as positive aspects of residing in a small locality, Additionally, many small localities, according to the answers, enjoy a reputation as 'a metal town', where there is a good atmosphere and sense of community among the bands in the genre. 
In contrast, the lack of concert venues, training facilities and music industry services, as well as the small size of the local music scene, were mentioned as negative aspects of small localities. Accordingly, in large cities the positive aspects were associated with the abundant availability of concert venues, music industry services, networking possibilities and an active metal music sub-culture offering strong potential for attracting large audiences. Harsh competition, i.e. the oversupply of metal music bands and the high costs of training facilities, were identified as negative aspects of large cities.

In terms of their hometowns, 29 bands were contemplating moving or had already moved from their current/original place of residence. It is notable that 19 of these 29 bands were from small localities. However, the major motives for moving included factors other than those strictly related to the music industry: for instance, their day-to-day jobs, studying and familyrelated reasons. Nonetheless, some bands, especially those with a record deal (i.e. the ones that are more likely to make their living out of music), reported reasons related to the music industry: some members of the bands had moved or were contemplating moving in order to be closer to the other band members and training facilities, due to the better supply and demand conditions for music in large cities, and in order to promote their international careers. In contrast, some bands reported that there was really no need for the bands or their members to move from their current hometowns due to the ease of file-sharing and other means of Internet communication. The technological developments that have enabled independent bands to reach the global market irrespective of their home locality have also enabled bands with a record deal to communicate with other key players in the music industry without being geographically close to them.

In general, networking with other bands was more common than networking with firms or organizations (Table I). Moreover, for Finnish metal music bands, having a manager is rare. More commonly, the booking agencies also take care of the managerial services for the bands, 
explaining the low scores in the questionnaire. Mann-Whitney U-tests show indifference in terms of the importance of local and extra-local networks in relation to the size of the localities that the bands reside in. Thus, according to the statistical analysis, local and extra-local networks are equally important (or unimportant) for bands both in the large cities as well as in the small localities. However, what is still evident from the results is the higher importance of firms and organizations outside rather than inside the hometowns of bands residing in small localities. The size of these small localities seems to be insufficient to cater for the needs of the bands in terms of professional help from music industry firms and organizations. Due to low demand, these services are not commonly available in small towns. In this sense, extra-local networks are more important for bands in small localities than in large cities. In contrast, it was verified that the bands that had a record deal were more engaged, than the independent ones, with firms and organizations outside their home locality and with foreign bands. Thus, it is not the size of the city but rather the independent vs. record deal difference that plays the key role in explaining the evolution of networks between local and extra-local bands, firms and organizations. The relatively small sample size might affect the validity of these results. However, the mean values of bands from large and small localities were so similar (Table I) that it is highly unlikely that a larger sample would have changed this tendency significantly.

\section{$<$ Table I about here>}

The open-ended questions gave further support for the statistical results presented above. For example, in several answers the importance of (social) networks was highlighted as being essential in working in the same music genre: "It is only natural that you collaborate with others bands inside the genre; you cannot manage these things on you own", and "The collaboration with other bands gives us visibility and creates networks, which are necessary for operating in 
this field". The pragmatic economic aspects of networking were also highlighted: joint gigs to attract larger audiences as well as lending instruments and equipment are commonplace. The fact that most musicians in small localities know each other adds to this, since there seem to be strong feelings of solidarity between the bands in the metal music genre as the musicians frequently are friends: "Collaboration feels a natural way of doing business, especially since the circles are small and almost everyone knows everyone". The reasons why bands reported a lack of connections with other local bands were to do with practical issues such as time constraints and the lack of local bands in the same genre in small localities. However, some bands reported that they had bad experiences from previous partnerships i.e. the competition between the bands has led to a certain wariness: "The competitiveness of the genre shows: musicians can talk trash about other bands to promote their own".

The engagement with local firms and organizations arose out of a "love for the community" i.e. the bands wanted to support local entrepreneurs. Of course the ease of faceto-face communications, and familiarity with the people one is doing business with, made a significant contribution to fostering local interaction: "All the actors in this field feed each other; it would be odd if we would not be tied to local businesses and organization in the music industry", and "In many cases the fact that one has existing ties to these firms/actors has a significant influence on the selection of partners". Accordingly, the most obvious reason for the lack of engagement with local firms and organizations was simply that there are none, as reported by the majority of the bands residing in small localities: "The actors discussed in this questionnaire are largely absent in our small hometown; the music business in Finland is heavily concentrated in the HMA". However, at the same time some of the independent bands were confident that they can do most of the work by themselves without the aid of local (or extra-local) firms. 
The connections with extra-local and foreign bands were described in terms of "you scratch my back, I'll scratch yours" activity, especially when it comes to touring together, whereas engagement with extra-local firms and organizations depended on the availability of these actors at the local scale. If these services/functions cannot be catered for locally, they have to be acquired extra-locally. Furthermore, active interaction with extra-local and foreign bands, firms and organizations was deemed in certain cases to be a necessity for reaching larger markets. In fact, many of the bands which had a record deal had signed this with a foreign record company. The reasons for not having extra-local networks were to do with the limited connections of (especially novice) bands outside their home locality.

To conclude, the open ended questions reveal that the reasons behind networking, or the lack thereof, remained more or less the same irrespective of the geographical scale.

\section{Discussion and conclusions}

In relation to the importance of local and extra-local networks in the creative industries, it seems that city size plays some role: in small and peripheral localities, dense local networks are largely absent and the bands interact through extra-local networks (global pipelines), whereas in large cities the importance of local networks (local buzz) is more marked. The questionnaire results corroborate the view that bands from small localities network more with extra-local than local firms and organizations compared to bands from large cities, where the music industry seems to agglomerate. This is due to the lack of these services in their home locality. Nevertheless, many bands and independent musicians decide to reside outside the large urban centres. This is due to the positive aspects of smaller cities including a good atmosphere, sense of community and inexpensive training facilities. However, because of the lack of concert venues, music industry services and the unimpressive size of the local metal music scene in many small localities, some bands and artists were contemplating moving to a 
larger city with better networking possibilities and larger audiences, even though the harsher competition and higher costs of these cities were acknowledged. These issues are in line with earlier research on the geography of the music industry (e.g. Florida and Jackson 2010; Hracks et al. 2011) and the specificities of the distribution of metal bands across Finland (Makkonen 2014).

The results have wider applicability in terms of the discussion revolving around local buzz and global pipelines in general and the networking patterns of creative industries in particular: the general principles expressed in the earlier literature (e.g. Matters 2012) when discussing the networking patterns of creative industries (i.e. the heightened importance of geographical proximity, local buzz and local networks) do not hold entirely in the light of the evidence presented here. It seems that even small towns can host creative teams without the existence of large numbers of potential local partners, which has commonly been advocated as being necessary for the emergence of successful creative localities. Thus, extra-local networks seem to be, at least (in some distinct cases), as important, and interaction within them as frequent, as the existence of local ones for creative teams to thrive in a given locality. Moreover, it seems that the issue of record deals plays a more prominent role than the city size in explaining the evolution of networks in the Finnish metal music genre: bands with a record deal interact more intensively, than independent bands, with other bands, firms and organizations outside their home localities. Accordingly, the geographical scale of connections was deemed in many ways to be relatively unimportant, as is apparent from the open-ended questions concerning the reasons behind networking (at least partly due to technological advancements in file sharing and communication). Thus, geographical scale is, after all, not as significant a factor in explaining the evolution of networks inside the music industry as could be expected based on the earlier literature on the importance of local buzz in creative industries. In sum, it seems that it is not that essential where the people one knows and interacts with 
reside, as long as one knows them. For the geography of the creative industries, and the music industry in particular, this is an interesting and important implication. It contests, at least to a certain degree, the current emphasis given to the importance of geographical proximity and the way that creative industries are supposed to network, which is supposedly mainly locally.

\section{Acknowledgements}

I am grateful to Mr Ville Karttunen from Juki Records for his comments on the nature and organization of the Finnish music industry, to the questionnaire respondents for their time and effort, to the anonymous referees for their comments on improving the paper and to Professor Allan Williams for his help with the language editing.

\section{References}

Asheim B, Coenen L and Vang J 2007 Face-to-face, buzz and knowledge bases: socio-spatial implications for learning, innovation and innovation policy Environment and Planning C 25 655-70

Asheim B and Hansen H 2009 Knowledge bases, talents, and contexts: on the usefulness of the creative class approach in Sweden Economic Geography 85 425-42

Bathelt H, Malmberg A and Maskell P 2004 Clusters and knowledge: local buzz, global pipelines and the process of knowledge creation Progress in Human Geography 28 31-56

Baulch E 2003 Gesturing elsewhere: the identity politics of the Balinese death/thrash metal scene Popular Music 22 195-215

Bayer G 2009 Heavy Metal Music in Britain Ashgate, Farnham

Belussi F and Sedita S 2008 The management of events in the Veneto performing music cluster in Cooke P and Lazzaretti L eds Creative Cities, Cultural Clusters and Local Economic Development Edward Elgar, Cheltenham 237-57

Brandellero A and Pfeffer K 2011 Multiple and shifting geographies of world music production Area $43495-505$ 
Braunerhjelm P 2009 The genesis and evolution of the Stockholm music cluster in Karlsson C, Andersson Å, Cheshire P and Stought $\mathbf{R}$ eds New Directions in Regional Economic Development Springer, Berlin 385-408

Brown A, O'Connor J and Cohen S 2000 Local music policies within a global music industry: cultural quarters in Manchester and Sheffield Geoforum 31 437-51

Chu Y-W and Leung E 2013 Remapping Hong Kong popular music: covers, localisation and the waning hybridity of Cantopop Popular Music 32 65-78

Connell J and Gibson C 2004 World music: deterritorializing place and identity Progress in Human Geography 28 342-61

Coulson S 2012 Collaborating in a competitive world: musicians' working lives and understandings of entrepreneurship Work, Employment and Society 26 246-61

Cummins-Russell T and Rantisi N 2012 Networks and place in Montreal's independent music industry Canadian Geographer 56 80-97

Dunn S 2004 Lands of fire and ice: an exploration of death metal scenes Public 29 106-25

Florida R 2005 Cities and the Creative Class Routledge, New York

Florida R and Jackson S 2010 Sonic city: the evolving economic geography of the music industry Journal of Planning Education and Research 29 310-21

Florida R, Mellander C and Stolarick K 2010 Music scenes to music clusters: the economic geography of music in the US Environment and Planning A 42 785-804

Fløysand A and Jakobsen S-E 2007 Commodification of rural places: a narrative of social fields, rural development and football Journal of Rural Studies 23 206-21

Friman M, Korhonen E and Räikkönen M 2013 Music as the gate to Finnish culture Interdisciplinary Studies Journal 2 164-9

Gertler M and Wolfe D 2006 Spaces of knowledge flows in Asheim B, Cooke P and Martin R eds Clusters and Regional Development Routledge, London 218-35

Gibson C and Davidson D 2004 Tamworth, Australia's country music capital: place marketing, rurality and resident reactions Journal of Rural Studies 20 387-404 
Grant J and Kronstal K 2010 The social dynamics of attracting talent in Halifax Canadian Geographer 54 347-65

Harris K 2000 "Roots?": the relationship between the global and the local within the extreme metal scene Popular Music 19 13-30

Harrison L 2010 Factory music: how the industrial geography and working-class environment of postwar Birmingham fostered the birth of heavy metal Journal of Social History 44 145-58

Hauge A and Hracs B 2010 See the sound, hear the style: collaborative linkages between indie musicians and fashion designers in local scenes Industry and Innovation 17 113-29

Hjelm T, Kahn-Harris K and Levine M 2013 Heavy Metal: Controversies and Countercultures Equinox, Sheffield

Hracs B, Grant J, Haggett J and Morton J 2011 A tale of two scenes: civic capital and retaining musical talent in Toronto and Halifax Canadian Geographer 55 365-82

Hracs B and Leslie D 2014 Aesthetic labour in creative industries: the case of independent musicians in Toronto, Canada Area 46 66-73

Johansson $\mathbf{O}$ and Bell T 2009 Where are the new US music scenes in Johansson O and Bell T eds Sound, Society and the Geography of Popular Music Ashgate, Aldershot 219-44

Kahn-Harris K 2002 "I hate this fucking country": dealing with the global and the local in the Israeli extreme metal scene Critical Studies 19 119-36

Kahn-Harris K 2004 The "failure" of youth culture: reflexivity, music and politics in the black metal scene European Journal of Cultural Studies 7 95-111

Kahn-Harris K 2007 Extreme Metal: Music and Culture on the Edge Berg, Oxford

Kloosterman R 2005 Come together: an introduction to music and the city Build Environment 31 18191

Laaksonen L, Ainamo A and Karjalainen T-M 2011 Entrepreneurial passion: an explorative study of four metal music ventures Journal of Research in Marketing and Entrepreneurship 13 18-36

Lange B and Bürkner H-J 2013 Value creation in scene-based music production: the case of electronic club music in Germany Economic Geography 89 149-69

Maguire D 2015 Determinants of the production of heavy metal music Metal Music Studies 1 155-69 
Makkonen T 2014 Tales from the thousand lakes: placing the creative network of metal music in Finland Environment and Planning A 46 1586-1600

Martin R 2013 Differentiated knowledge bases and the nature of innovation networks European Planning Studies 21 1418-36

Matters J 2012 Dimensions of proximity and knowledge bases: innovation between spatial and nonspatial factors Regional Studies 46 1085-99

Mayer A and Timberlake J 2014 The fist in the face of god: heavy metal music and decentralized cultural diffusion Sociological Perspectives 57 27-51

Metal from Finland 2013 Home Page (www.metalfromfinland.com) Accessed 30 December 2013

Mould O and Joel S 2010 Knowledge networks of 'buzz' in London's advertising industry: a social network analysis approach Area 42 281-92

Scott A 2010 Cultural economy and the creative field of the city Geografiska Annaler B 92 115-30

Snell D and Hodgetts D 2007 Heavy metal, identity and the social negotiation of a community of practice Journal of Community and Applied Psychology 17 430-45

Ter Wal A and Boschma R 2009 Applying social network analysis in economic geography: framing some key analytic issues Annals of Regional Science 43 739-56

van Heur B 2009 The clustering of creative networks: between myth and reality Urban Studies 46 $1531-52$

Watson A 2008 Global music city: knowledge and geographical proximity in London's recorded music industry Area 40 12-23

Watson A 2012 The world according to iTunes: mapping urban networks of music production Global Networks 12 446-66 
Table I. Summary of the bands' local and extra-local engagements. Average rating on a scale where $1=$ often and $7=$ seldom.

\begin{tabular}{|c|c|c|c|c|c|c|}
\hline & \multicolumn{2}{|c|}{ Record deal } & \multicolumn{4}{|c|}{ City size } \\
\hline & Yes & No & P-value* & Large & Small & P-value* \\
\hline \multicolumn{7}{|l|}{ Local bands } \\
\hline Guest performances & 3.4 & 3.3 & & 3.4 & 3.3 & \\
\hline Touring/gigs & 4.6 & 4.9 & & 4.9 & 4.6 & \\
\hline Instruments/equipment & 4.2 & 4.4 & & 4.1 & 4.5 & \\
\hline Other activities & 4.0 & 3.9 & & 4.2 & 3.7 & \\
\hline Sum variable $(\alpha=0.724)$ & 4.0 & 4.1 & 0.892 & 4.1 & 4.0 & 0.621 \\
\hline \multicolumn{7}{|l|}{ Local firms/organizations } \\
\hline Managers & 1.6 & 1.5 & & 1.6 & 1.5 & \\
\hline Record companies & 1.6 & 1.4 & & 1.7 & 1.3 & \\
\hline Publishing companies & 1.3 & 1.3 & & 1.4 & 1.2 & \\
\hline Studios & 3.4 & 3.4 & & 3.3 & 3.5 & \\
\hline Booking agencies & 2.9 & 2.3 & & 2.9 & 2.1 & \\
\hline Sound and lighting & 3.4 & 2.8 & & 2.5 & 3.6 & \\
\hline Concert venues & 5.0 & 4.9 & & 5.3 & 4.5 & \\
\hline Fan products & 2.3 & 1.9 & & 1.6 & 2.5 & \\
\hline Copyright societies & 2.1 & 1.9 & & 2.5 & 1.5 & \\
\hline Sum variable $(\alpha=0.721)$ & 2.6 & 2.4 & 0.313 & 2.6 & 2.4 & 0.667 \\
\hline Sum variable local ( $\alpha=0.769)$ & 3.0 & 2.9 & 0.509 & 3.0 & 2.9 & 0.746 \\
\hline \multicolumn{7}{|l|}{ Extra-local (domestic/national) bands } \\
\hline Guest performances & 3.3 & 2.6 & & 3.0 & 2.8 & \\
\hline Touring/gigs & 5.0 & 4.4 & & 4.5 & 4.9 & \\
\hline Instruments/equipment & 3.2 & 3.2 & & 3.2 & 3.2 & \\
\hline Other activities & 3.1 & 2.6 & & 2.9 & 2.7 & \\
\hline Sum variable $(\alpha=0.673)$ & 3.7 & 3.2 & 0.163 & 3.4 & 3.4 & 0.810 \\
\hline \multicolumn{7}{|c|}{ Extra-local (domestic/national) firms/organizations } \\
\hline Managers & 2.4 & 1.4 & & 1.4 & 2.3 & \\
\hline Record companies & 4.3 & 2.0 & & 2.9 & 3.1 & \\
\hline Publishing companies & 2.9 & 1.5 & & 1.8 & 2.4 & \\
\hline Studios & 3.0 & 2.3 & & 2.4 & 2.8 & \\
\hline Booking agencies & 4.3 & 2.0 & & 2.7 & 3.3 & \\
\hline Sound and lighting & 2.6 & 2.0 & & 1.9 & 2.6 & \\
\hline Concert venues & 5.6 & 4.4 & & 4.8 & 5.0 & \\
\hline Fan products & 2.3 & 1.6 & & 1.5 & 2.4 & \\
\hline Copyright societies & 3.1 & 2.4 & & 1.9 & 3.5 & \\
\hline Sum variable $(\alpha=0.875)$ & 3.4 & 2.2 & $<0.001$ & 2.4 & 3.0 & 0.040 \\
\hline Sum variable extra-local $(\alpha=0.865)$ & 3.5 & 2.5 & $<0.001$ & 2.7 & 3.2 & 0.176 \\
\hline \multicolumn{7}{|c|}{ Extra-local (foreign/international) bands } \\
\hline Guest performances & 2.3 & 1.5 & & 1.8 & 1.9 & \\
\hline Touring/gigs & 3.6 & 2.3 & & 3.0 & 2.7 & \\
\hline Instruments/equipment & 2.6 & 1.9 & & 2.5 & 2.0 & \\
\hline Other activities & 2.2 & 1.8 & & 2.3 & 1.7 & \\
\hline Sum variable $(\alpha=0.843)$ & 2.7 & 1.9 & 0.008 & 2.4 & 2.1 & 0.743 \\
\hline \multicolumn{7}{|c|}{ Extra-local (foreign/international) firms/organizations } \\
\hline Managers & 2.7 & 1.5 & & 1.7 & 2.3 & \\
\hline Record companies & 3.7 & 2.3 & & 3.0 & 2.9 & \\
\hline Publishing companies & 2.6 & 1.6 & & 1.9 & 2.1 & \\
\hline Studios & 1.7 & 1.3 & & 1.6 & 1.3 & \\
\hline Booking agencies & 3.1 & 1.8 & & 2.3 & 2.5 & \\
\hline Sound and lighting & 1.8 & 1.3 & & 1.5 & 1.5 & \\
\hline Concert venues & 3.2 & 1.9 & & 2.5 & 2.4 & \\
\hline Fan products & 2.3 & 1.5 & & 1.8 & 1.9 & \\
\hline Copyright societies & 1.7 & 1.6 & & 1.5 & 1.8 & \\
\hline Sum variable $(\alpha=0.894)$ & 2.5 & 1.6 & $<0.001$ & 2.0 & 2.1 & 0.949 \\
\hline Sum variable foreign $(\alpha=0.901)$ & 2.6 & 1.7 & $<0.001$ & 2.1 & 2.1 & 0.910 \\
\hline
\end{tabular}

